\title{
Effects of a drug overdose in a television drama on knowledge of specific dangers of self poisoning: population based surveys
}

\author{
Susan O'Connor, Jonathan J Deeks, Keith Hawton, Sue Simkin, Allison Keen, Douglas G Altman, \\ Greg Philo, Christopher Bulstrode
}

Editorial by Collee

United Bristol Healthcare Trust, Directorate of Mental Health, Barrow Hospital, Bristol BS19 3SG Susan O'Connor, consultant psychiatrist continued over

BMJ 1999;318:978-9

\section{Subjects, methods, and results}

The episode (described in detail in accompanying arti$\mathrm{cle}^{3}$ ) depicted a man suffering potentially fatal liver damage after an untreated paracetamol overdose. Although the particular dose (50 tablets) and delay before presentation (2 days) were mentioned, the episode did not specify minimal toxic doses or maximum safe delays.

At one week and 32 weeks after this episode was broadcast, we sent questionnaires to members of the BBC Television Opinion Panel. Panel members are recruited by structured sampling to be representative of the adult UK population and are sent weekly questionnaires related to their viewing. At one week after the broadcast, we asked them whether they had viewed the relevant Casualty episode and questions to test their knowledge of the delayed hepatotoxic effects of paracetamol in overdose, maximum safe delays before seeking help, and fatal doses of several drugs commonly used for self poisoning (see table). The test questions were repeated at 32 weeks after the

Responses to the survey questions testing knowledge of paracetamol toxicity 1 week and 32 weeks after broadcast of an episode of Casualty depicting a paracetamol overdose: comparison of the knowledge of those who did and did not see the episode. Values are numbers (percentages) of those who responded to question unless stated otherwise

\begin{tabular}{|c|c|c|c|c|c|c|c|}
\hline \multirow[b]{3}{*}{ Question and responses } & \multicolumn{3}{|c|}{ Responses 1 week after broadcast } & \multicolumn{4}{|c|}{ Responses 32 weeks after broadcast } \\
\hline & \multirow[b]{2}{*}{$\begin{array}{l}\text { Viewers } \\
(\mathrm{n}=1030)\end{array}$} & \multirow[b]{2}{*}{$\begin{array}{c}\text { Non-viewers } \\
(n=1762)\end{array}$} & $\begin{array}{l}\text { Odds ratio }(95 \% \mathrm{Cl}) \text { for viewers } v \\
\text { non-viewers; } \mathrm{P} \text { value }\end{array}$ & \multirow[b]{2}{*}{$\begin{array}{l}\text { Viewers } \\
(\mathrm{n}=475)\end{array}$} & \multirow[b]{2}{*}{$\begin{array}{c}\text { Non-viewers } \\
(\mathrm{n}=807)\end{array}$} & \multicolumn{2}{|c|}{$\begin{array}{l}\text { Odds ratio }(95 \% \mathrm{Cl}) \text { for viewers } v \\
\text { non-viewers; } \mathrm{P} \text { value }\end{array}$} \\
\hline & & & $\begin{array}{c}\text { Adjusted }^{*} \\
(\mathrm{n}=1168)\end{array}$ & & & $\begin{array}{c}\text { Crude } \\
(\mathrm{n}=1282)\end{array}$ & $\begin{array}{c}\text { Adjusted }^{*} \\
(n=1168)\end{array}$ \\
\hline \multicolumn{8}{|l|}{ Delayed effects of paracetamol } \\
\hline \multicolumn{8}{|c|}{$\begin{array}{l}\text { Question: An overdose of one of the following drugs will make a person unwell to start with, then they may feel better, but a few days later they may die from liver damage. Can you say which } \\
\text { drug has this effect? Answers: antibiotics, aspirin, Brufen, paracetamol, sleeping tablets, tranquillisers, don't know }\end{array}$} \\
\hline Correct (paracetamol) & $877(85)$ & $786(45)$ & \multirow{2}{*}{$\begin{array}{cc}\text { OR for giving correct answer† } \\
5.03(3.75 \text { to } 6.75) ; & 4.79(2.63 \text { to } 8.71) ; \\
\mathrm{P}<0.0005 & \mathrm{P}<0.0005\end{array}$} & $361(76)$ & $392(49)$ & \multirow{2}{*}{\multicolumn{2}{|c|}{$\begin{array}{cc}\text { OR for giving correct answert } \\
2.60(1.77 \text { to } 3.83) ; & 2.32(1.42 \text { to } 3.81) ; \\
\mathrm{P}<0.0005 & \mathrm{P}=0.001\end{array}$}} \\
\hline Incorrect (other drug) & $61(6)$ & $275(16)$ & & $40(8)$ & $113(14)$ & & \\
\hline Don't know or no answerł & $92(9)$ & $701(40)$ & & $74(16)$ & $302(37)$ & & \\
\hline \multicolumn{8}{|l|}{ Delay in presentation§ } \\
\hline \multicolumn{8}{|c|}{ Question: What is the latest response time after an overdose of this drug that a person can seek help to avoid this fatal effect? Answers: $6,12,24,48$ or 72 hours, or don't know } \\
\hline 6 hours & $305(35)$ & $292(37)$ & \multirow{4}{*}{$\begin{array}{cc}\text { OR for reporting shorter timesf } \\
0.67 \begin{array}{cc}(0.54 \text { to } 0.83) ; & 0.62(0.40 \text { to } 0.94) ; \\
P<0.0005 & P=0.02\end{array}\end{array}$} & $138(38)$ & $133(34)$ & \multirow{4}{*}{\multicolumn{2}{|c|}{$\begin{array}{cc}\text { OR for reporting shorter times } \\
0.84(0.62 \text { to } 1.14) ; & 0.69(0.45 \text { to } 1.05) ; \\
P=0.3 & P=0.08\end{array}$}} \\
\hline 12 hours & $172(20)$ & $159(20)$ & & $89(25)$ & $91(23)$ & & \\
\hline 24 hours & $121(14)$ & $59(8)$ & & $43(12)$ & $41(10)$ & & \\
\hline 72 hours & $13(1)$ & $10(1)$ & & $5(1)$ & $3(1)$ & & \\
\hline Don't know or no answerł & $211(24)$ & $240(31)$ & & $66(18)$ & $119(30)$ & & \\
\hline \multicolumn{8}{|l|}{ Fatal dose of paracetamol } \\
\hline \multicolumn{8}{|c|}{ Question: What number of tablets of paracetamol do you think could kill a person? Answers: $15,30,50$, or 100 tablets, or don't know } \\
\hline 15 & $258(25)$ & $369(21)$ & \multirow{4}{*}{$\begin{array}{cc}\text { OR for reporting lower dosesfl } \\
0.91(0.77 \text { to } 1.06) ; & 0.80(0.57 \text { to } 1.11) ; \\
P=0.2 & P=0.18\end{array}$} & $140(29)$ & $214(27)$ & \multirow{4}{*}{\multicolumn{2}{|c|}{$\begin{array}{c}\text { OR for reporting lower dosesf } \\
0.94(0.74 \text { to } 1.21) ; \quad 0.75(0.53 \text { to } 1.04) ; \\
P=0.6 \quad P=0.09\end{array}$}} \\
\hline 30 & $233(23)$ & $365(21)$ & & $120(25)$ & $171(21)$ & & \\
\hline 50 & $276(27)$ & $247(14)$ & & $72(15)$ & $100(12)$ & & \\
\hline 100 & $67(7)$ & $144(8)$ & & $29(6)$ & $43(5)$ & & \\
\hline Don't know or no answerł & $196(19)$ & $637(36)$ & & $114(24)$ & $279(35)$ & & \\
\hline \multicolumn{8}{|c|}{ Comparative toxicity of paracetamol } \\
\hline \multicolumn{8}{|c|}{$\begin{array}{l}\text { Question: What number of tablets of each of the following drugs do you think could kill a person? Antibiotics, aspirin, Brufen, paracetamol, sleeping tablets, tranquillisers. Answers: For each } \\
\text { drug dose stated as } 15,30,50 \text { or } 100 \text { tablets, or don't know. Drugs then ranked according to responses }\end{array}$} \\
\hline Paracetamol singly most toxic & $145(14)$ & $177(10)$ & \multirow{3}{*}{$\begin{array}{l}\text { OR for ranking paracetamol as more toxic } \text { ? } \\
\begin{array}{cc}1.04(0.86 \text { to } 1.26) ; & 0.92(0.63 \text { to } 1.35) ; \\
P=0.7 & P=0.7\end{array}\end{array}$} & $88(19)$ & $82(10)$ & \multirow{3}{*}{\multicolumn{2}{|c|}{$\begin{array}{l}\text { OR for ranking paracetamol as more toxicf } \\
1.40(1.04 \text { to } 1.87) ; \quad 1.16(0.79 \text { to } 1.71) ; \\
P=0.03 \quad P=0.4\end{array}$}} \\
\hline Paracetamol jointly most toxic & $570(55)$ & $796(45)$ & & $236(50)$ & $399(49)$ & & \\
\hline Other drug more toxic & $119(12)$ & $152(9)$ & & $37(8)$ & $47(6)$ & & \\
\hline Don't know or no answerł & $196(19)$ & $637(36)$ & & $114(24)$ & $279(35)$ & & \\
\hline
\end{tabular}

${ }^{*}$ Adjusted for age, sex, social class, region, medical viewing habits, self reported medical interest, and general medical knowledge assessed by responses to two test questions. †Odds ratios (OR) estimated from logistic regression analyses for dichotomous outcomes.

fFor all questions, viewers were significantly less likely $(\mathrm{P}<0.001)$ not to respond or to respond "don't know" than non-viewers. These responses were excluded from further analyses. $\S 0$ ly participants who correctly identified paracetamol as the drug causing liver damage are included in this analysis.

१Odds ratios (OR) estimated from proportional odds models for ordinal outcomes, comparing the odds of viewers and non-viewers responding with more appropriate responses of any degree. 
broadcast, together with further questions about members' interest in medical matters and viewing of other medical dramas and documentaries. General medical knowledge was tested by two multiple choice questions: "What is a crash team?" and "What is a laparotomy?" Responses from the two surveys were linked. At one week, 2792 out of 3115 panel members participated, $1030(37 \%)$ of whom reported watching the episode. At 32 weeks, 1282 of these participants remained in the panel, of whom $475(37 \%)$ had seen the episode.

Non-viewers were more likely not to respond or respond "don't know" to all questions in both surveys. At one week, significantly more viewers $(85 \%)$ than non-viewers $(45 \%)$ correctly identified paracetamol as having hepatotoxic effects. By 32 weeks, this knowledge had declined by $12 \%$ in viewers $(\mathrm{P}<0.0005)$ and increased by $5 \%$ in non-viewers $(\mathrm{P}=0.004)$. The effects were little changed by using a logistic regression model to adjust for demographic factors and measures of medical interest, knowledge, and viewing habits.

Viewers indicated longer minimal safe delays before seeking help than non-viewers, the differences being small but significant. There was no difference between viewers and non-viewers in lethal doses of paracetamol or the ranking of paracetamol toxicity compared with that of other drugs.

\section{Comment}

Rates of deliberate self harm continue to increase: overdose is the most common method, and paracetamol the most commonly used substance. ${ }^{1}$ Baseline knowledge in this study was high: $45 \%$ of those who did not see the episode knew of the delayed hepatotoxicity of paracetamol, possibly reflecting recent extensive media attention.
Television is an important potential source of medical information, ${ }^{4}$ with programmes such as Casualty attracting audiences of over 10 million. Our study showed that viewers of a Casualty episode registered and retained information about paracetamol toxicity presented in the programme among other distracting story lines. Interestingly, it also revealed that the knowledge obtained was strictly restricted to the presented facts and that incomplete messages might have been misinterpreted. There was also an increase in overdose presentations to general hospitals after the broadcast." Medical messages broadcast within television programmes are likely to have an impact on the knowledge of the general public: editors should be aware of this and ensure that they are accurate and complete.

We thank the BBC for its help with this project, in particular, Barbara Machin (script writer Casualty), Christine Hamar Brown (script editor Casualty), the Casualty production team, the $\mathrm{BBC}$ television opinion panel, the BBC Information Department, and Dr G Hughes (consultant to Casualty).

Contributors: All authors participated in the design of the study and preparing the report. SO'C and $\mathrm{KH}$ designed the questionnaires. SO'C and JJD took major responsibility for analysing the results, interpreting the findings, and preparing the report. AK coordinated data collection, DGA provided statistical advice. CB initiated the study. SO'C is guarantor for the study.

Funding: The study was funded by the Nuffield Trust. KH and SS were also supported by Anglia and Oxford NHS Executive Research and Development Committee.

Competing interests: None declared.

1 Hawton K, Fagg J, Simkin S, Bale E, Bond A. Trends in deliberate self harm in Oxford 1985-95. Br J Psychiatry 1997:171:556-60.

Bray G. Liver failure induced by paracetamol. BMJ 1993;306:157-8

3 Hawton K, Simkin S, Deeks JJ, O'Connor S, Keen A, Altman DG, et al. Effects of a drug overdose in a television drama on presentations to hospital for self poisoning: time series and questionnaire study. $B M$ J 1999;318:972;7.

4 Gunnell D. Reporting suicide. The effects of media coverage on patterns of self harm. BMJ 1994;308:1446-7.

(Accepted 18 March 1999)
ICRF/NHS Centre for Statistics in Medicine, Institute of Health Sciences, Oxford OX3 7LF Jonathan J Deeks, medical statistician

Douglas G Altman, director

University of Oxford,

Department of

Psychiatry,

Warneford Hospital, Oxford OX3 7JX

Keith Hawton, professor of psychiatry Sue Simkin, research assistant

University of Oxford, Nuffield Department of Orthopaedic Surgery, John

Radcliffe Hospital,

Oxford OX3 9DU

Allison Keen, research assistant

Christopher Bulstrode, professor of orthopaedics

Glasgow University Media Unit, Glasgow G12 8LF Greg Philo research director

Correspondence to: Dr O'Connor

\section{An important lesson TB or not TB}

I arranged for the admission of my younger sister with a deep sense of apprehension. The kind medical registrar I spoke to did his best to allay my anxieties, but he too agreed that urgent admission and assessment were warranted. Over the past two to three months she had developed symptoms of weight loss, recurrent fevers and night sweats, together with bilateral cervical lymphadenopathy. Examination on admission also showed the presence of splenomegaly. A series of investigations was promptly initiated.

When my parents asked what was wrong, I said that she was likely to be suffering from tuberculosis. Consciously I had decided not to raise the possibility of a lymphoma, hoping to protect them from stress and worry, which I sincerely hoped was unnecessary. To my mind, tuberculosis was a far more welcome possibility than a mother of three young children developing a lymphoma-with B symptoms at the age of 26. My answer failed to have the desired response, for reasons, which at the time, I could not fully understand.

Last week, almost a year on, my father spoke about his younger sister who developed tuberculosis at a similar age. I cannot really remember him speaking about her at any length before. Fighting back the tears he recalled how she had been quarantined, away from her family. On the few occasions that I was taken to visit her she would, I was told, gently kiss my tiny feet on seeing me, hoping to avoid passing on her lethal disease. Cure? There was no cure for tuberculosis in Pakistan at the time.

Initial tests for tuberculosis on my sister were negative, as were the fine needle aspirate and lymph node excision biopsy that followed. Histology showed no evidence of malignancy. Thankfully, she has in time made a full recovery, from what turned out to be a self limiting condition.

During the course of my general practice training I was taught the importance of exploring the fears, anxieties, and concerns of patients and their families, thereby attempting to place events, health, and disease in the context of their very personal narratives. Last week, I was reminded of the truth of this teaching.

Aziz Sheikh, clinical research fellow in general practice, London

We welcome articles of up to 600 words on topics such as A memorable patient, A paper that changed my practice, My most unfortunate mistake, or any other piece conveying instruction, pathos, or humour. If possible the article should be supplied on a disk. Permission is needed from the patient or a relative if an identifiable patient is referred to. We also welcome contributions for "Endpieces," consisting of quotations of up to 80 words (but most are considerably shorter) from any source, ancient or modern, which have appealed to the reader. 